\title{
Laboratory assessment of tetrakis(hydroxymethyl)phosphonium sulfate as dissolver for scales formed in sour gas wells
}

\author{
Q. Wang, ${ }^{1 *}$ S. Shen, ${ }^{1}$ H. Badairy, ${ }^{1}$ T. Shafai, ${ }^{1}$ Y. Jeshi, ${ }^{1}$ T. Chen ${ }^{2}$ \\ and F. F. Chang ${ }^{2}$
}

${ }^{1}$ Saudi Aramco, Research and Development Center, Dhahran, Saudi Arabia 31311

${ }^{2}$ Saudi Aramco, EXPEC Advanced Research Center, Dhahran, Saudi Arabia 31311

*E-mail:qiwei.wang@aramco.com

\begin{abstract}
Tetrakis(hydroxymethyl)phosphonium sulfate (THPS) is an environmental friendly biocide commonly used in oil fields. It also has been used to control iron sulfide precipitation for water injection and to remove deposits in oil production systems. In this study, THPS was examined as the dissolver for scale deposits formed on downhole tubular of high temperature sour gas wells. These deposits consisted of a wide range of mineral phases and are often dominated with various forms of iron sulfides and iron oxyhydroxides. The THPS based dissolvers were studied at various concentrations, $\mathrm{pH}$ values and with different additives. These additives included ammonium chloride, chelating agents and phosphonates. Experimental results indicated that the dissolving power was not proportional to THPS concentration. The maximum dissolution was observed in THPS concentration of 25 to $50 \%$, depending on scale composition. Its dissolving power could be significantly increased with both ammonium chloride and chelating agents. The synergistic effect of ammonium chloride was largely attributed to $\mathrm{pH}$ decrease. As a result, the corrosivity of THPS solution to metallurgy was increased with the addition of ammonium chloride. The corrosion rate of mild steel was increased over three times with $4 \%$ ammonium chloride added. Contrary to previous reports, phosphonate additives decreased scale dissolution and induced new precipitation. Formation of calcium sulfate precipitates was also observed during dissolution of calcite, which will limit the THPS from scales containing calcium carbonate. This study also revealed the dissolution behavior of different minerals in the THPS solution. Iron oxyhydroxides had the highest dissolution rate, followed by calcite, siderite and pyrrhotite. Pyrite, marcasite and anhydrite were almost insoluble in the tested solutions. Results from this study can be used as guideline for the development and design of THPS based scale dissolvers.
\end{abstract}

Keywords: iron sulfide, iron scale, scale dissolver, THPS, gas well.

Received: June 8, 2015

doi: $\underline{10.17675 / 2305-6894-2015-4-3-235-254}$ 


\section{Introduction}

Tetrakis(hydroxymethyl)phosphonium sulfate, commonly referred to as THPS, is a commercial product in organophosphine derivatives. Flame retardant for cotton and viscose fabrics is one of the most important uses of this product [1,2]. It is also applied in hydrometallurgical extraction and leather tanning processes, for curing of epoxies, in phase transfer catalysis, and for preservation of coatings, pigments and slurries $[3,4]$. In the oil and gas industry, THPS is primarily utilized as a biocide to control sulfate reducing bacteria due to its enhanced performance, higher thermal stability and low foaming potential [5-8]. Unlike conventional biocides, which are highly toxic to aquatic organisms and accumulative in the food chain, THPS has a relatively good environmental profile $[8,9]$. It can be degraded in both aerobic and anaerobic environments through hydrolysis, oxidation, biological and photo reactions [10]. The degradation reactions are affected by many factors such as temperature, $\mathrm{pH}$ value, $\mathrm{O}_{2}$ level, light, microbes and the presence of mild steel $[10,11]$. The breakdown products include trishydroxymethylphosphine oxide (THPO), bishydroxymethyl phosphonic acid (BMPA), and possibly a formaldehyde adduct of trihydroxy compound [12]. These compounds have low aquatic toxicity and are not considered as environmental hazard.

While used primarily as a biocide, THPS was also found being able to dissolve iron sulfide precipitates. Talbot et al. [13] studied the dissolution of iron sulfides in THPS based solutions over a range of conditions and showed that its performance was comparable to or even better than the uninhibited hydrochloric $(\mathrm{HCl})$ acid with actual field scale samples as well as pure authigenic minerals, particularly in combination with ammonium chloride or organic phosphonate scale inhibitor. In their study, the THPS also displayed an ability to dissolve pyrite, which is generally considered insoluble in hydrochloric acid [14]. Wylde and Winning [15] further investigated the dissolution properties of THPS solutions and evaluated different additives for synergistic effects using both static and dynamic dissolution testing procedures. They also concluded that the THPS blended dissolver performed at least as well as, and in some cases better than the $\mathrm{HCl}$ acid.

It is obvious that the aforementioned study results could be affected by many factors, such as test temperature, duration, scale to dissolver ratio and scale composition. Differing from other types of scale, both iron and sulfide have multiple redox states and, depending on the formation conditions, they can form precipitates with various compositions and dramatically different properties [16]. The identified scale minerals in petroleum industry include mackinawite $(\mathrm{FeS})$ and pyrrhotite $\left(\mathrm{Fe}_{1-x} \mathrm{~S}\right)$, troilite $(\mathrm{FeS})$, greigite $\left(\mathrm{Fe}_{3} \mathrm{~S}_{4}\right)$, and iron disulfide pyrite and marcasite $\left(\mathrm{FeS}_{2}\right)$ [17-19]. Each mineral has its distinct reactivity toward the dissolver. In addition, grain size, shape and the distribution of scale particle also affect their dissolution behaviors. Deposits may contain non-sulfide components such as carbonate, oxide and sulfate minerals. An efficient scale dissolver must be effective to all minerals under field application conditions.

Although the THPS based solutions showed good performance with deposits from water injectors and surface flowlines, their effectiveness on the scale formed under 
downhole environments remains to be studied. The objective of this work is to understand the effectiveness of THPS based dissolver to scale formed in high temperature sour gas wells. Alternative dissolvers are high desirable for downhole applications due to drawbacks associated with commonly used $\mathrm{HCl}$ acid dissolvers [20]. The aggressive nature of $\mathrm{HCl}$ acid can cause severe corrosion to downhole tubular at elevated temperatures [2124]. Dissolution reaction produces high concentration of toxic $\mathrm{H}_{2} \mathrm{~S}$ gas in low $\mathrm{pH}$ solutions. Loss of spent acid into reservoir can lead to formation damage in near wellbore area due to the re-precipitation of dissolved iron sulfide solids.

\section{Experimental}

\section{Dissolver solutions}

The dissolver solutions were prepared from a 75\% THPS commercial product. The variables studied included THPS concentration, $\mathrm{pH}$ and different additives. Additives consisted of ammonium chloride, phosphonates and chelating agents for potential synergistic effects. The phosphonates were two commonly used scale inhibitors: diethylenetriamine pentamethylene phosphonate (DETPMP) and bis(hexamethylene)triamine pentamethylene phosphonate (BHTPMP). Chelating agents included nitrilotriacetate (NTA), ethylenediaminetetraacetate (EDTA) and glutamic acid diacetate. All dissolver solutions were prepared on the base of weight percentage. Effect of $\mathrm{pH}$ and additives were studied by using solutions with $25 \%$ THPS. The $\mathrm{pH}$ adjustment was achieved by adding concentrated $\mathrm{HCl}$ or $\mathrm{NaOH}$ solution, and amounts of organic phosphate and chelating agent were kept at 5\%.

\section{Scale solids}

Scale solids used in this study were collected on downhole tubular of gas wells during well intervention. These gas wells produce from a carbonate reservoir and have downhole temperatures in the range of 135 to $160^{\circ} \mathrm{C}[25,26]$. The produced gases contain hydrogen sulfide $\left(\mathrm{H}_{2} \mathrm{~S}\right)$ up to $8 \mathrm{~mol} \%$ and carbon dioxide $\left(\mathrm{CO}_{2}\right)$ of $4-5 \mathrm{~mol} \%$ [25]. The produced water is a mixture of formation brine and condensation water, and the water production rates are very low (2 to $5 \mathrm{bbl} / \mathrm{MMscf}$ ) for most wells. Scale deposition on downhole tubular has been a persistent problem in this field since its early production days [27]. The deposit composition showed significant variations with sample and a wide range of inorganic minerals were identified. The iron-containing minerals were the dominant species in all samples analyzed, including different forms of sulfide, oxide, (hydr)oxide and carbonate. Calcite was found in most samples and anhydrite was also present in some cases. The deposit was an aggregation of small sized particles $(<20 \mu \mathrm{m})$ and the distribution of different types of particles was highly heterogeneous (Figure 1).

Table 1 summarizes the compositions of scale solids used in this study. They were collected in three different wells. Table 2 lists the $\mathrm{H}_{2} \mathrm{~S}$ and $\mathrm{CO}_{2}$ contents of produced gases from these wells. Both Scale \#A and \#C had significant amounts of calcite, whilst Scale \#B 
contained $50 \%$ iron (hydr)oxides and $11 \%$ siderite. Trace amounts $(\leq 3 \%)$ of barite, dolomite, elemental sulfur and quartz were also detected in these samples.
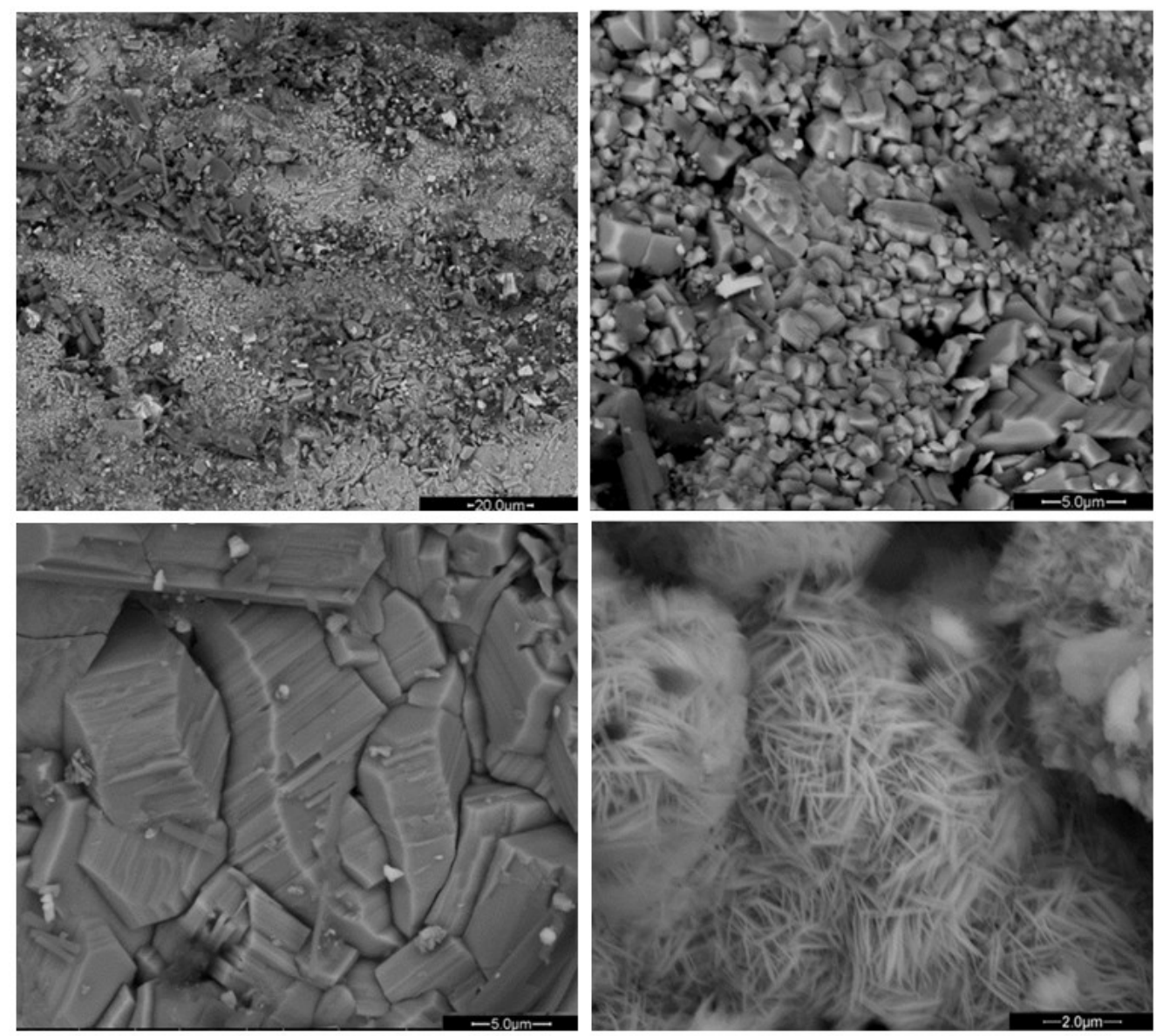

Figure 1. Microstructure of scale deposit.

Table 1. Scale compositions determined by XRD analysis.

\begin{tabular}{cccc}
\hline Scale Mineral & Scale \#A & Scale \#B & Scale \#C \\
\hline Pyrrhotite, $\mathrm{Fe}_{1-} \mathrm{S}$ & $38 \%$ & $21 \%$ & $56 \%$ \\
Mackinawite, $\mathrm{FeS}$ & $0 \%$ & $0 \%$ & $2 \%$ \\
Pyrite, $\mathrm{FeS}_{2}$ & $15 \%$ & $11 \%$ & $13 \%$ \\
Marcasite, $\mathrm{FeS}_{2}$ & $7 \%$ & $3 \%$ & $6 \%$ \\
Goethite, $\alpha-\mathrm{FeOOH}$ & $0 \%$ & $7 \%$ & $0 \%$ \\
Akaganeite, $\beta-\mathrm{FeO}(\mathrm{OH}, \mathrm{Cl})$ & $0 \%$ & $37 \%$ & $0 \%$ \\
Lepidocrocite, $\gamma-\mathrm{FeOOH}$ & $0 \%$ & $6 \%$ & $1 \%$ \\
Calcite, $\mathrm{CaCO}_{3}$ & $23 \%$ & $0 \%$ & $16 \%$ \\
Siderite, $\mathrm{FeCO}_{3}$ & $0 \%$ & $11 \%$ & $0 \%$ \\
Anhydrite, $\mathrm{CaSO}_{4}$ & $13 \%$ & $0 \%$ & $3 \%$ \\
\hline
\end{tabular}


Table 2. $\mathrm{H}_{2} \mathrm{~S}$ and $\mathrm{CO}_{2}$ content in produced gas.

\begin{tabular}{cccc}
\hline Mol.\% & Scale \#A & Scale \#B & Scale \#C \\
\hline $\mathrm{H}_{2} \mathrm{~S}$ & 4.4 & 3.0 & 2.0 \\
$\mathrm{CO}_{2}$ & 3.5 & 1.5 & 1.5 \\
\hline
\end{tabular}

Scale samples were pulverized for homogenization and powders with the size of 0.6 to $2.0 \mathrm{~mm}$ were collected. They were washed repeatedly with toluene till the solvent became clear for the removal of hydrocarbon and fine particles. Then the samples were rinsed with isopropyl alcohol (IPA) and dried in open air for overnight before use.

\section{Test procedure}

All experiments were performed at $85^{\circ} \mathrm{C}$. Each test used $3.00 \mathrm{~g}$ of scale powder and $30 \mathrm{ml}$ of dissolver fluid. Test tube filled with dissolver solution was placed into a preheated oven $\left(85^{\circ} \mathrm{C}\right)$ for 1 hour to equilibrate. After adding scale solid, the test tube was capped immediately, shaken vigorously for 15 seconds, and placed back to oven. The test tube was agitated for $\sim 5$ seconds after 15 minutes, then every 30 minutes for the first 8 hours and lastly after 23.5 hours. An aliquot of supernatant was withdrawn after 1, 2, 4, 8, and 24 hours. The liquid sample was preserved with $1 \% \mathrm{HCl}$ acid before inductively coupled plasma (ICP) analysis for dissolved Fe concentration. The remaining solid in test tube was collected by filtration with a $5 \mu \mathrm{m}$ filter paper, followed with $10 \mathrm{ml}$ of DI water to remove residual spent dissolver. Final solid weight was determined after drying at $45^{\circ} \mathrm{C}$ for overnight.

\section{Solid analysis}

Scale solids from selected runs were also examined with X-ray diffraction (XRD) and environmental scanning electron microscope (ESEM)/energy dispersive spectroscopy (EDS) to determine any composition changes. In the XRD analysis, the identification of the crystalline phases was achieved by using JADE 9.1+ program. The quantification of compounds present was performed using the Rietveld refinement method. For the ESEM analysis, the microscope was conducted at $15 \mathrm{kV}, 0.15$ Torr water vapor pressure, and $10 \mathrm{~mm}$ working distance. Backscattered electron surface morphological images along with EDS qualitative elemental compositional data were acquired.

\section{Corrosion test}

Corrosion tests were also performed to examine the effect of ammonium chloride additive on the corrosivity of THPS solutions. The experimental procedure was similar to that previously described [20]. Mild steel C1018 coupons were used and the test duration was 4 hours at $85^{\circ} \mathrm{C}$. Corrosion rate was calculated based on coupon weight change and surface area. 


\section{Results and Discussion}

\section{Effect of THPS concentration}

The dissolving power of THPS solutions at four concentrations (15, 25, 50 and 75\%) was evaluated with Scale \#A and B. Figure 2 shows the dissolved iron concentrations after different test durations. It is obvious that the scale dissolution was not proportional to the THPS concentration. The dissolved Fe concentration increased initially but started to decrease with further increase of THPS concentration. For tests with scale \#A, maximum dissolved $\mathrm{Fe}$ values were achieved in 50\% THPS solution for all test durations. The dissolution amounts with $75 \%$ THPS were similar to that with $25 \%$ THPS. For scale \#B, the highest Fe concentrations were observed in 25\% THPS solution for test durations of 1 , 2 , and 8 hours, and in 50\% THPS solution at test durations of 4 and 24 hours. Tests with scale \#B also showed that the $75 \%$ THPS solution had the least amount of dissolution. These observations could be caused by two factors. First, the dissolver stock solution contained species other than THPS compound. These species might act as inhibitors to retard the dissolution reaction. It was also possible that mass transfer rates of reactants and reaction products surrounding scale surface were decreased in high THPS solutions. Solution with high THPS concentration has increased viscosity, which results in an expanded diffusion boundary layer.

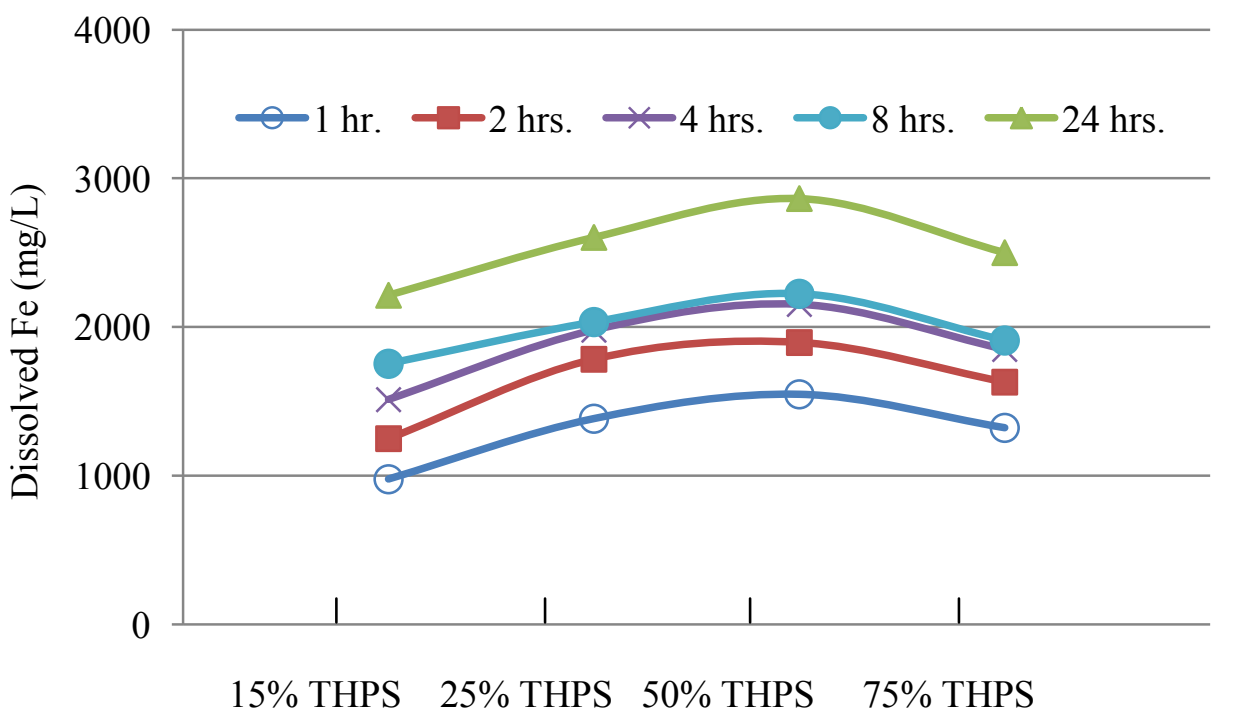

a). Scale \#A. 


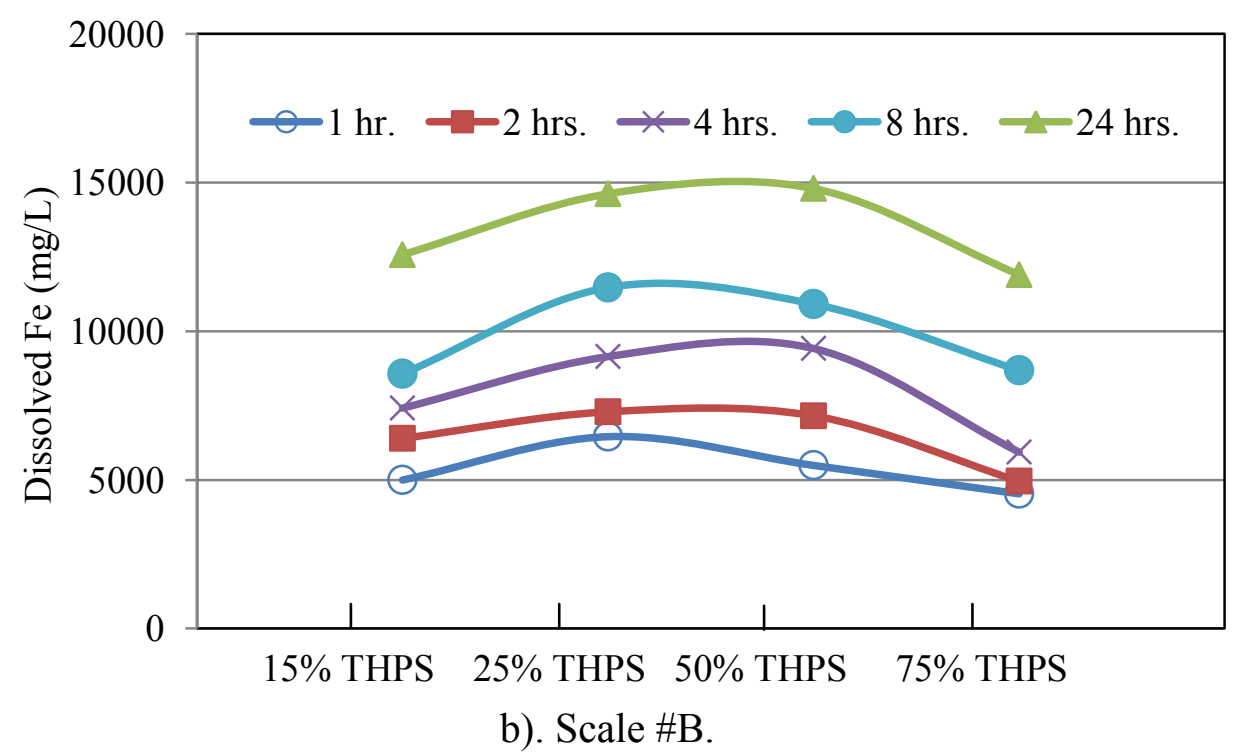

Figure 2. Effect of THPS concentration on scale dissolution.

Results listed in Figure 2 also indicate that the scale dissolution by THPS solution depends strongly on scale composition. In general, the dissolved Fe concentrations were $\sim 5$ times higher in test with scale \#B than that with scale \#A. These results may suggest a selective dissolution behavior of scale with mixed minerals. The ferric iron compounds, which were abundant in scale $\# \mathrm{~B}$, were more readily dissolved than iron sulfides by the THPS solutions. Low dissolved Fe concentrations with scale \#A might be also attributed to the presence of calcite. The dissolution of iron sulfides was limited because the dissolving power of the THPS solution was partially consumed by calcite.

Based on the dissolved $\mathrm{Fe}$ data, dissolution rate of scale solid was calculated for different reaction period (Figure 3). The dissolution rate decreased quickly as the progression of reaction. On average, the dissolution occurred in the first hour accounted for $\sim 50 \%$ and $\sim 40 \%$ of total dissolution during 24 hours for scale \#A and \#B, respectively. The dissolution rate in the first hour was $\sim 40$ times of the dissolution rate during 4 to 24 hour period for scale \#A and $\sim 20$ times for scale \#B. As the dissolving power is gradually spent, a decrease of dissolution rate with time was expected. Besides, the particles with high specific surface area and high solubility were dissolved preferably in the early stage of reaction. The remaining solids became progressively less reactive and they had low intrinsic dissolution rates even in fresh THPS solutions. 


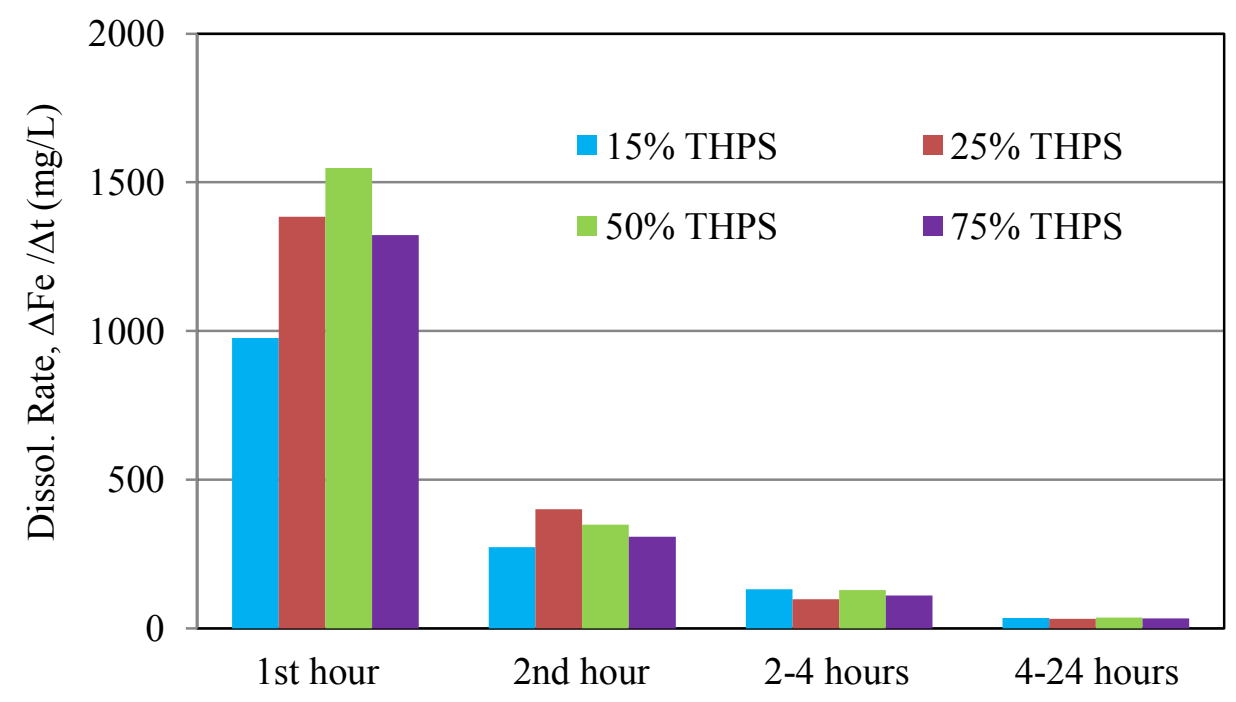

a). Scale \#A.

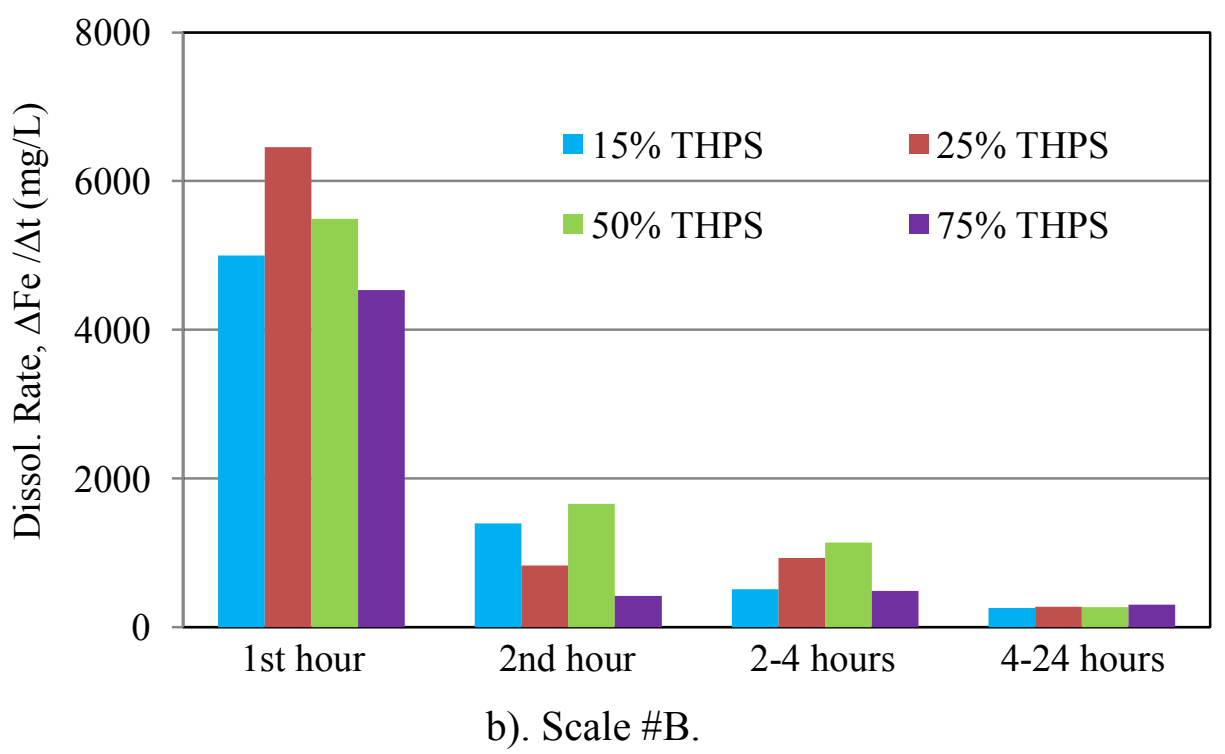

Figure 3. Changes of dissolution rate with time in THPS solutions.

\section{Effect of $\mathrm{NH}_{4} \mathrm{Cl}$ and $\mathrm{pH}$}

Significant increase in scale dissolution was observed with the addition of $\mathrm{NH}_{4} \mathrm{Cl}$ salt to the THPS solution. Figure 4 presents the test results with $25 \%$ THPS solutions. With scale \#A, the dissolved Fe value increased from 1384 to $3875 \mathrm{mg} / \mathrm{L}$ with $2 \% \mathrm{NH}_{4} \mathrm{Cl}$ and further to $5720 \mathrm{mg} / \mathrm{L}$ with $4 \% \mathrm{NH}_{4} \mathrm{Cl}$ after 1 hour. For the 24-hour test duration, the increases were from 2604 to $8497 \mathrm{mg} / \mathrm{L}$ with $2 \% \mathrm{NH}_{4} \mathrm{Cl}$ and to $14576 \mathrm{mg} / \mathrm{L}$ with $4 \% \mathrm{NH}_{4} \mathrm{Cl}$. Similar results were also obtained in tests with scale $\# \mathrm{~B}$, although the degree of increase was smaller (Figure $4 \mathrm{~b}$ ). The dissolved Fe concentrations were almost doubled by adding $2 \%$ $\mathrm{NH}_{4} \mathrm{Cl}$. With the addition of $4 \% \mathrm{NH}_{4} \mathrm{Cl}$, the dissolution amounts became $\sim 2.5$ times higher. 


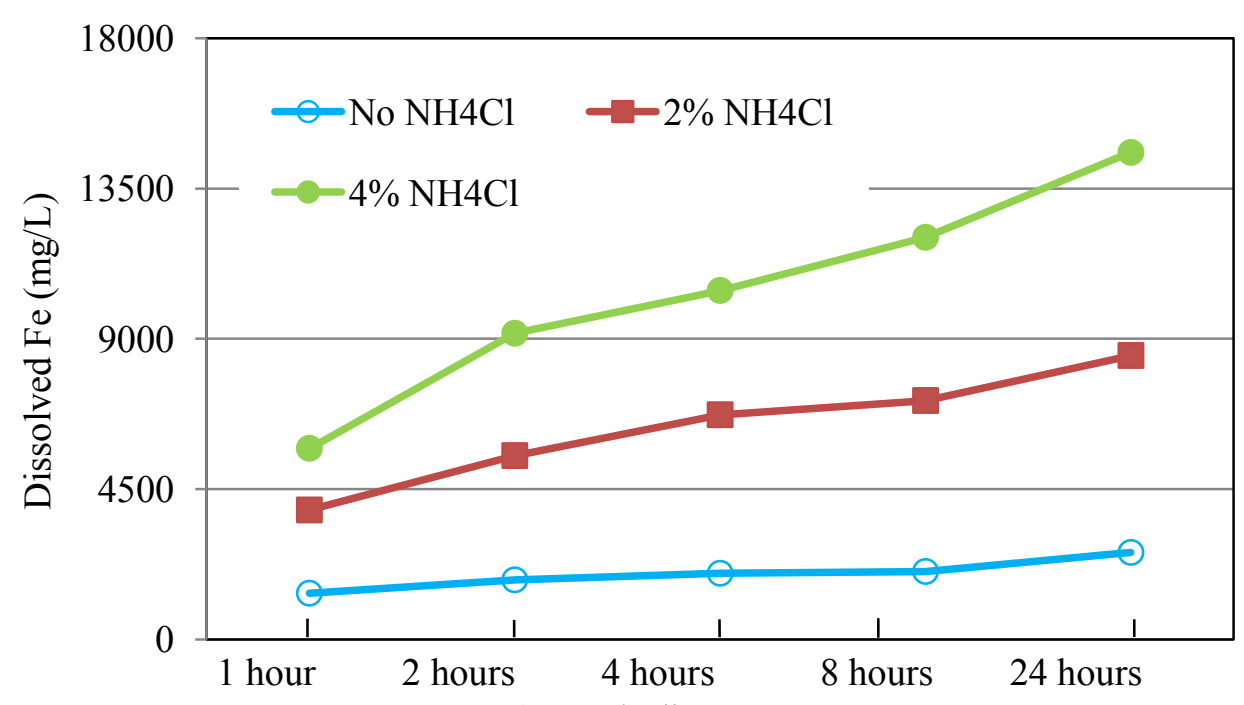

a). Scale \#A.

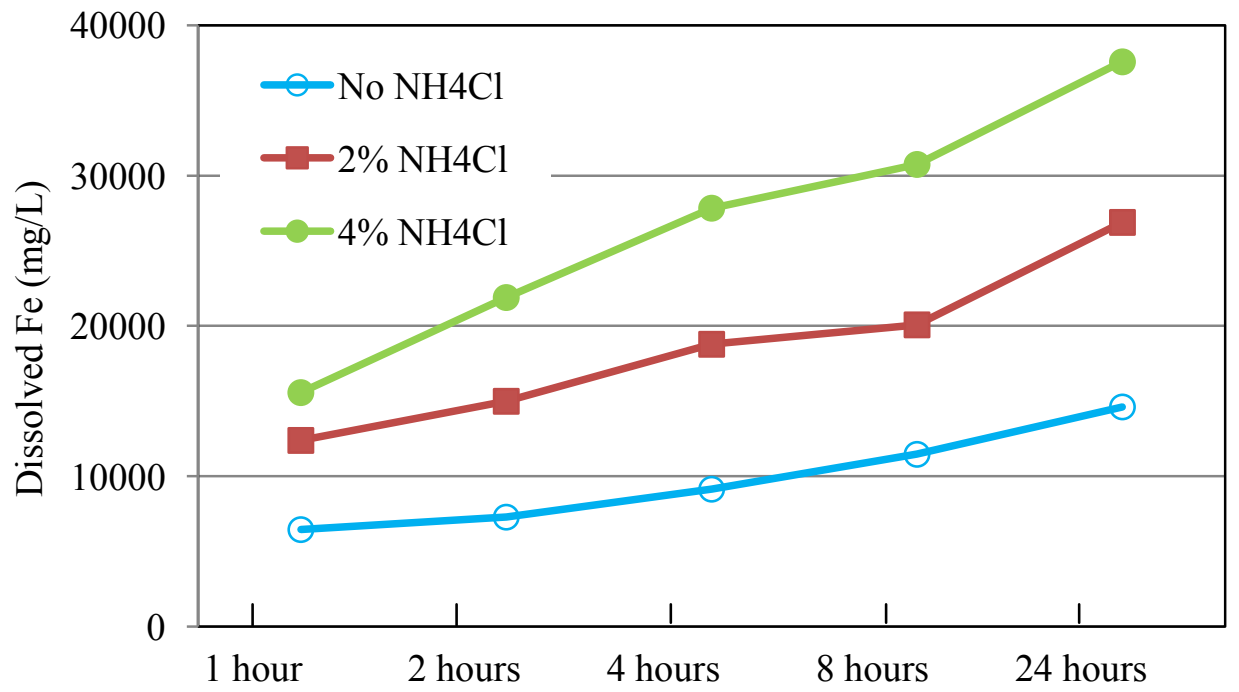

b). Scale \#B.

Figure 4. Effect of $\mathrm{NH}_{4} \mathrm{Cl}$ on scale dissolution by $25 \%$ THPS solution.

The change of dissolution rate with time was the same in 25\% THPS solutions with and without $\mathrm{NH}_{4} \mathrm{Cl}$ additives (Figure 5). A majority of the dissolution occurred in the first 2 hours. For all three solutions presented in Figure 5, the dissolution rates during the first 2-hour period were 20 to 30 times faster than in the last 20 hours. 


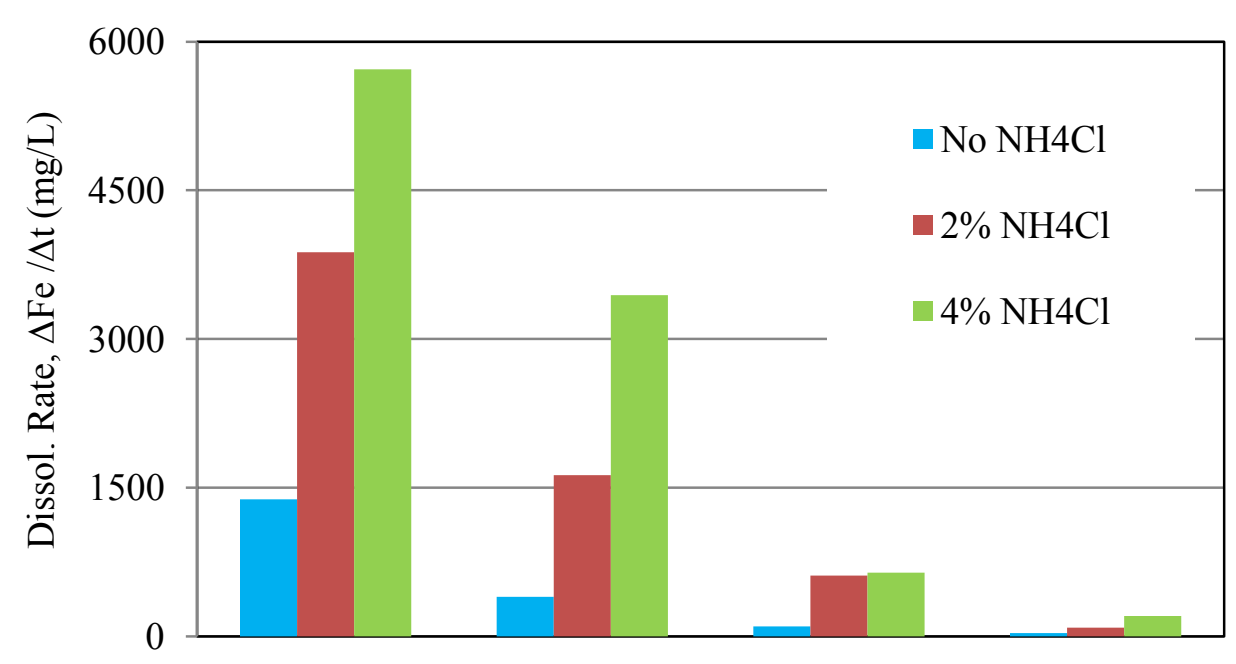

a). Scale \#A.

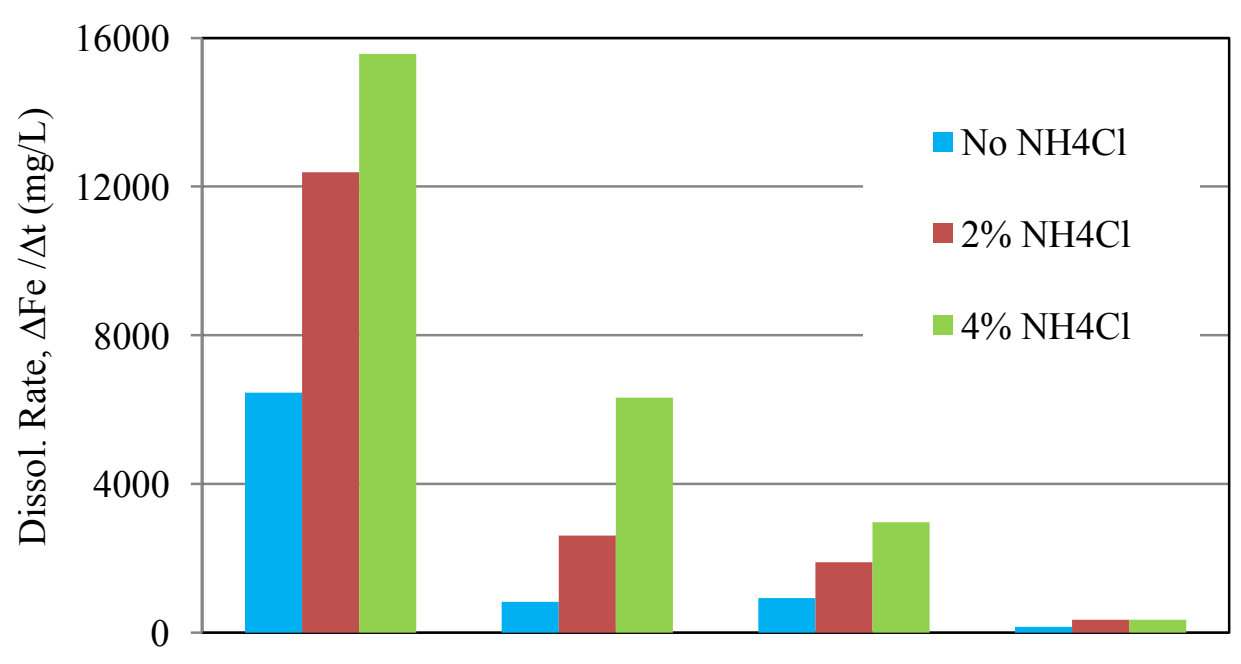

b). Scale \#B.

Figure 5. Changes of dissolution rate with time in 25\% THPS solutions.

It was also noticed that the spent dissolver solution had a much lower $\mathrm{pH}$ value when $\mathrm{NH}_{4} \mathrm{Cl}$ was used, as listed in Figure 6 for tests with scale \#B. Although the initial $\mathrm{pH}$ was slightly affected by $\mathrm{NH}_{4} \mathrm{Cl}$ addition, the solution became much more acidic at the end of test. Without $\mathrm{NH}_{4} \mathrm{Cl}$ additive, solution $\mathrm{pH}$ was increased from 3.3 to 5.2 due to scale dissolution. The $\mathrm{pH}$ value was almost unchanged for solution containing $2 \% \mathrm{NH}_{4} \mathrm{Cl}$. In the presence of $4 \% \mathrm{NH}_{4} \mathrm{Cl}, \mathrm{pH}$ was decreased to 1.5 even at the end of test. Such behavior was further illustrated with the additional tests. After the solutions were heated at $85^{\circ} \mathrm{C}$ for 1 hour and then cooled to room temperature, the $\mathrm{pH}$ value was decreased from 3.2 to 1.0 for solution with $2 \% \mathrm{NH}_{4} \mathrm{Cl}$ and from 3.1 to $<0.5$ for solution with $4 \% \mathrm{NH}_{4} \mathrm{Cl}$. 


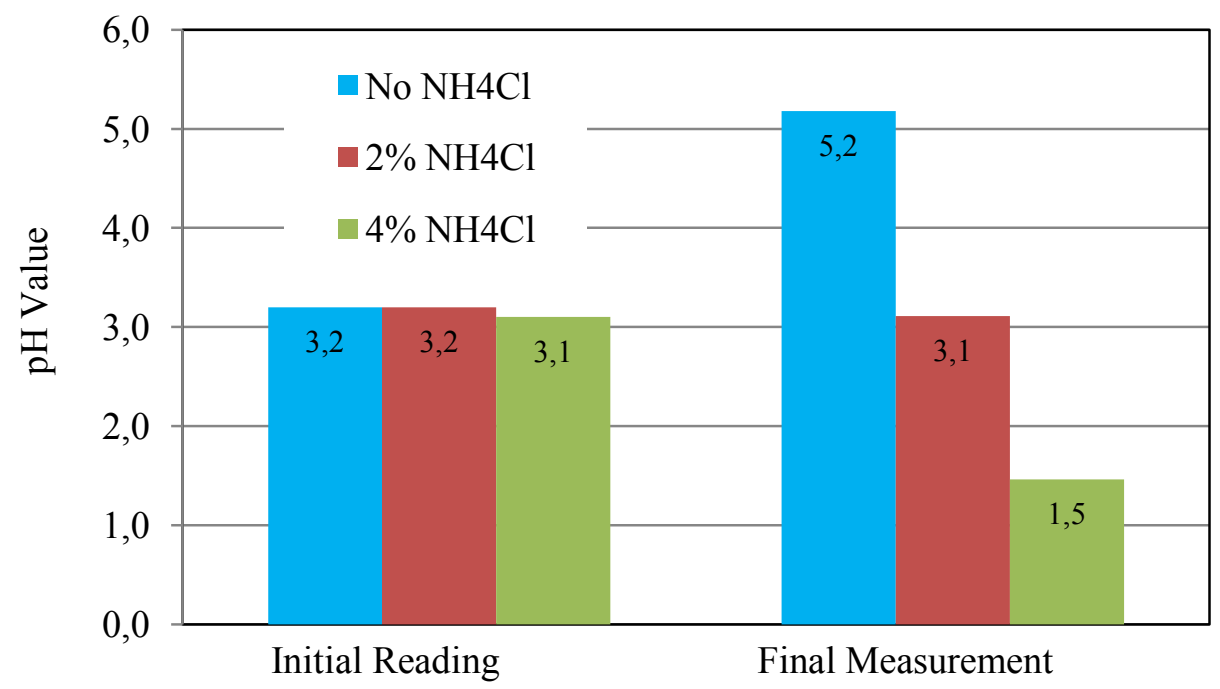

Figure 6. Change of solution $\mathrm{pH}$ with $\mathrm{NH}_{4} \mathrm{Cl}$ additive.

This $\mathrm{pH}$ decrease was a result of thermal decomposition at elevated temperature. Although stable at ambient conditions in the THPS solution, $\mathrm{NH}_{4} \mathrm{Cl}$ breaks down into ammonia $\left(\mathrm{NH}_{3}\right)$ and $\mathrm{HCL}$ acid at test temperature:

$$
\mathrm{NH}_{4} \mathrm{Cl} \stackrel{\text { Heat }}{\longrightarrow} \mathrm{NH}_{3}+\mathrm{HCl}
$$

This is equivalent to adding acid to the dissolver solution. To demonstrate the effect of $\mathrm{pH}$, tests were conducted by adjusting dissolver $\mathrm{pH}$ with $\mathrm{HCl}$ and $\mathrm{NaOH}$. Test results with scale \#A are presented in Figure 7. Reducing $\mathrm{pH}$ to 0.6 with $\mathrm{HCl}$ resulted in significant increases in dissolved Fe concentrations, similar to $\mathrm{NH}_{4} \mathrm{Cl}$ addition. On the other hand, dissolution was reduced when $\mathrm{pH}$ was raised to 4.9. These results suggest that the improvement of THPS performance by $\mathrm{NH}_{4} \mathrm{Cl}$, at least partially, was related to the lowered $\mathrm{pH}$ level of dissolver solutions.

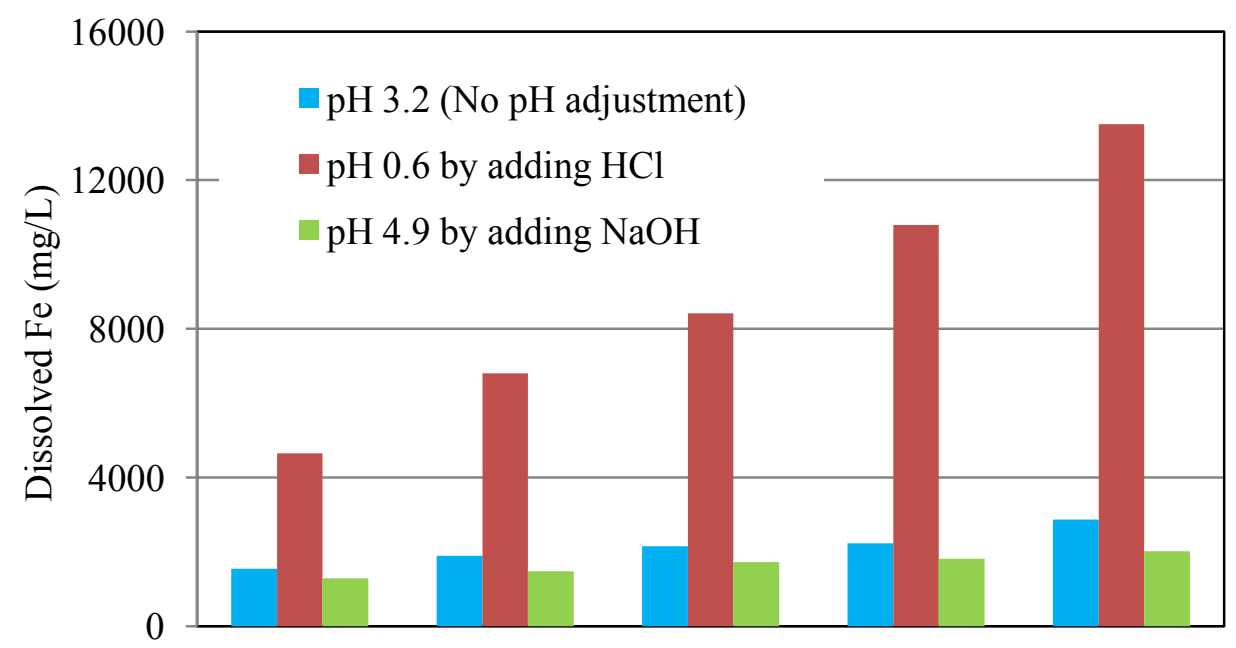

Figure 7. Effect of $\mathrm{pH}$ on scale dissolution by THPS dissolver. 
Reduction in solution $\mathrm{pH}$ diminishes the advantages of THPS as alternative scale dissolver. The solution becomes more corrosive toward well metallurgy. The potential damage to well integrity is an important factor in consideration of scale dissolving treatment. The corrosion test results are summarized in Figure 8. A large increase in corrosivity to mild carbon steel was observed. Coupon weight loss increased from $<0.02 \mathrm{lb} / \mathrm{ft}^{2}$ to over $0.05 \mathrm{lb} / \mathrm{ft}^{2}$ with $2 \% \mathrm{NH}_{4} \mathrm{Cl}$ and $0.06 \mathrm{lb} / \mathrm{ft}^{2}$ with $4 \% \mathrm{NH}_{4} \mathrm{Cl}$ in the 4 -hour tests. Also, more dissolved sulfide ions will be in $\mathrm{H}_{2} \mathrm{~S}$ form as $\mathrm{pH}$ decreases, escalating the potential of a hazardous working environment related to $\mathrm{H}_{2} \mathrm{~S}$ relapses.

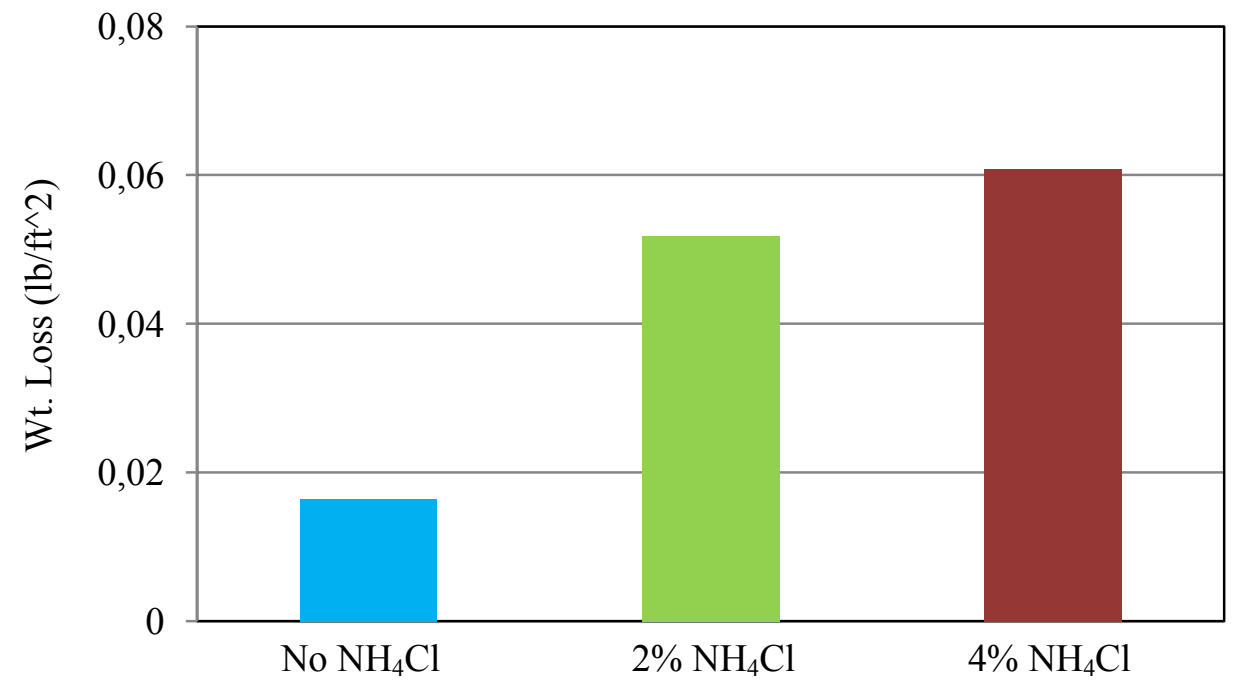

Figure 8. Effect of $\mathrm{NH}_{4} \mathrm{Cl}$ on THPS solution corrosivity.

\section{Effect of Organic Phosphate Additives}

The addition of phosphonate to $25 \%$ THPS solution did not improve scale dissolution in this study. Instead, the dissolved iron concentrations decreased with the addition of DETPMP and BHTPMP organic phosphates in all test durations (Figure 9). The synergistic effects reported previously could be caused by $\mathrm{pH}$ reduction with the use of strong acidic phosphonate chemicals. Light colored solids were observed in the remaining scale, suggesting that new type of solids was formed during test. Microscopic analysis showed that these new solids were small sized nodules $(1-2 \mu \mathrm{m})$ with a smooth surface (Figures 10 and 11). The EDS analysis indicated that they were rich in phosphorous element, suggesting the additive was the main reactant in the precipitation reaction. 


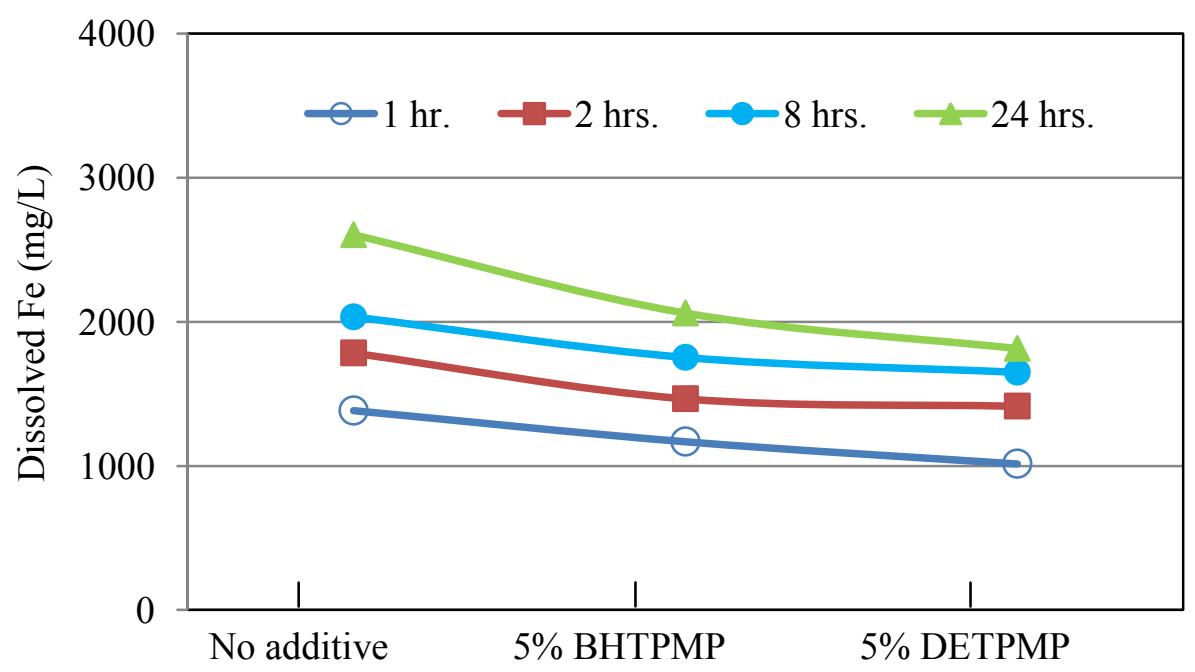

Figure 9. Effect of phosphonate additive on scale dissolution.

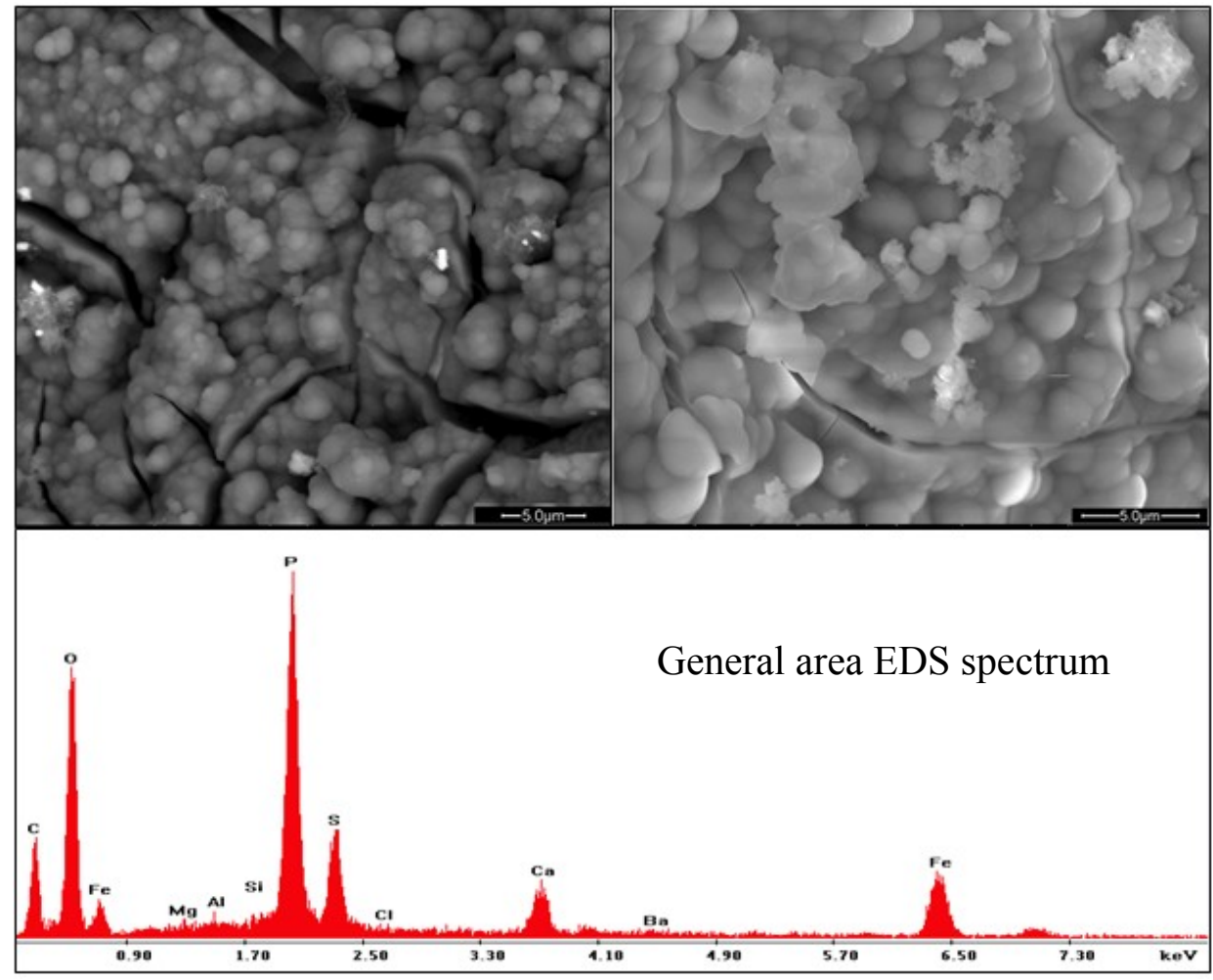

Figure 10. Solids formed in THPS solution with DETPMP additive. 


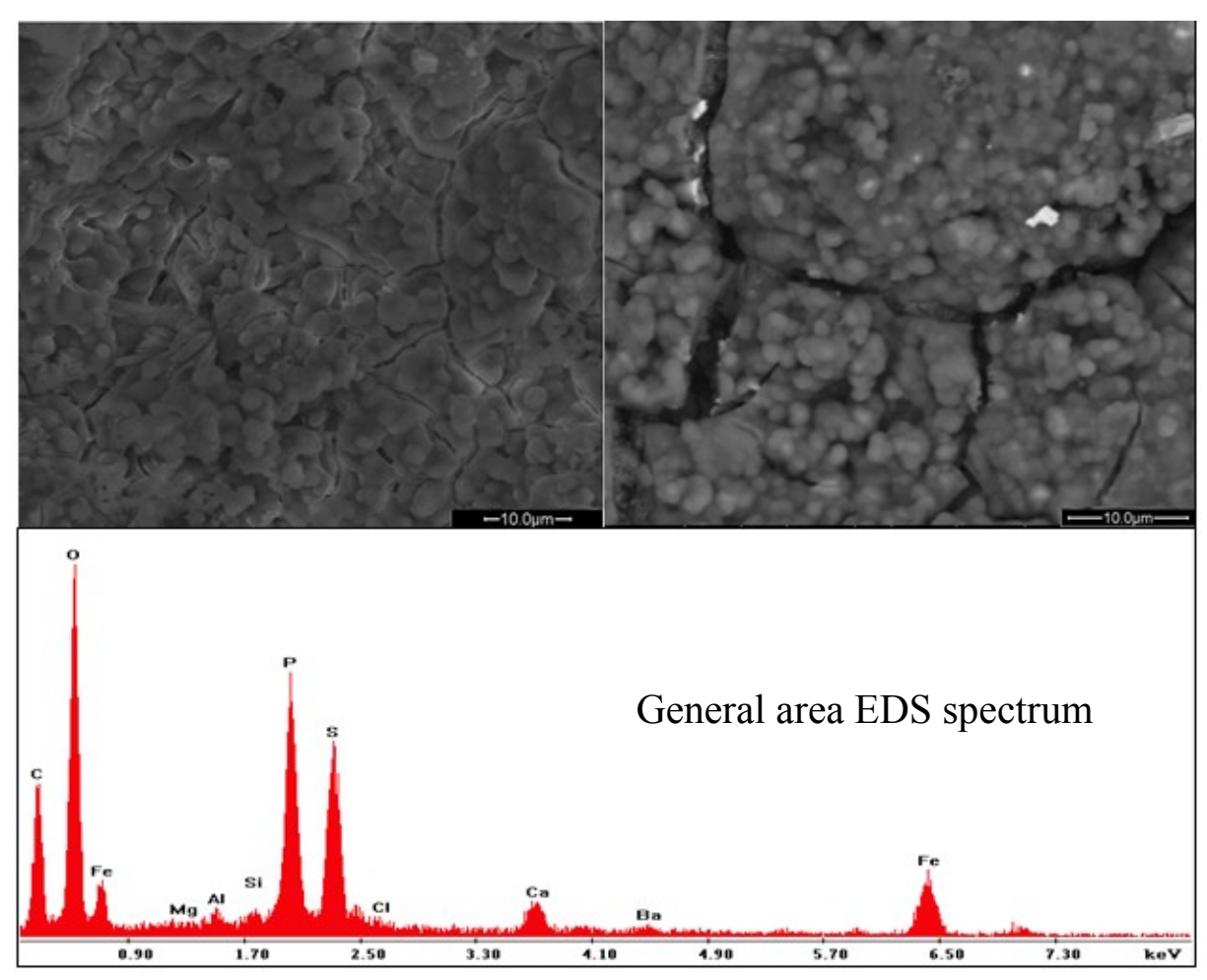

Figure 11. Solids formed in THPS solution with BHTPMP additive.

\section{Effect of Chelating Agents}

Addition of chelating agent improved the performance of THPS solution. Both dissolved Fe concentration and scale weight loss showed substantial increases with the addition of $5 \%$ chelating agents (Figures 12). These tests were performed scale \#C. GLDA and EDTA were more effective than NTA. This difference could be due to much higher $\mathrm{pH}$ value in NTA added solution $(\mathrm{pH} \sim 6.0)$ than others $(\mathrm{pH} 3.2-4.2)$. Trisodium nitrilotriacetate $\left(\mathrm{C}_{6} \mathrm{H}_{6} \mathrm{NNa}_{3} \mathrm{O}_{6}\right)$, its solution has an alkaline $\mathrm{pH}$ value, was used in this study. It is also interesting to note that the solutions with chelating agent additives had much smaller $\mathrm{pH}$ changes than the simple $25 \%$ THPS solution (Figure 13).

\section{Change in Scale Composition}

XRD analyses indicated the changes of scale composition after exposure to the THPS| solutions. The weight of each individual mineral was estimated from the weight $\%$ determined by XRD and the total scale weight. Selected results are shown in Figure 14. The estimation results showed that the pyrrhotite, calcite and siderite were partially dissolved, while iron disulfide (pyrite, marcasite) and anhydrite were mostly unchanged. Iron oxyhydroxides, including goethite, akaganeite and lepidocrocite, were the most reactive mineral phase to the THPS dissolvers. Over $70 \%$ of these compounds were dissolved in the $25 \%$ THPS solution after 24 hours and they were completely solubilized in solution with $4 \% \mathrm{NH}_{4} \mathrm{Cl}$ additive. 


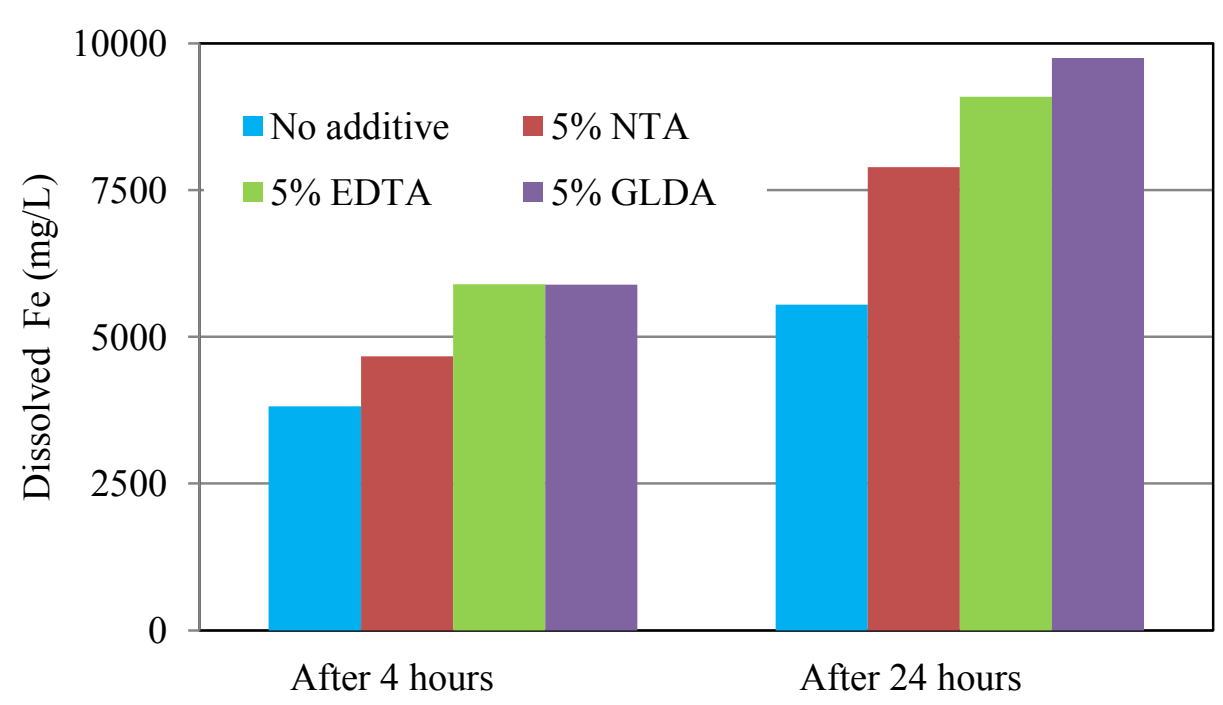

a). Dissolved Fe concentration.

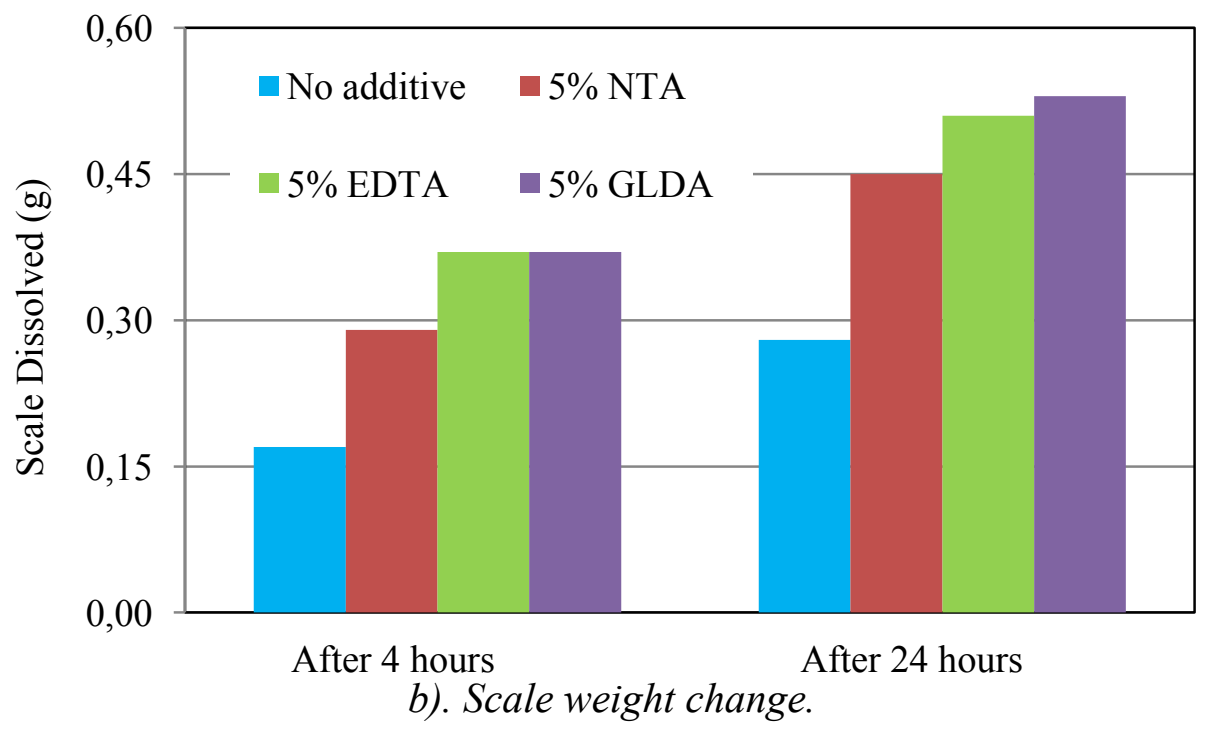

Figure 12. Effect of chelating agent on scale dissolution by THPS solution.

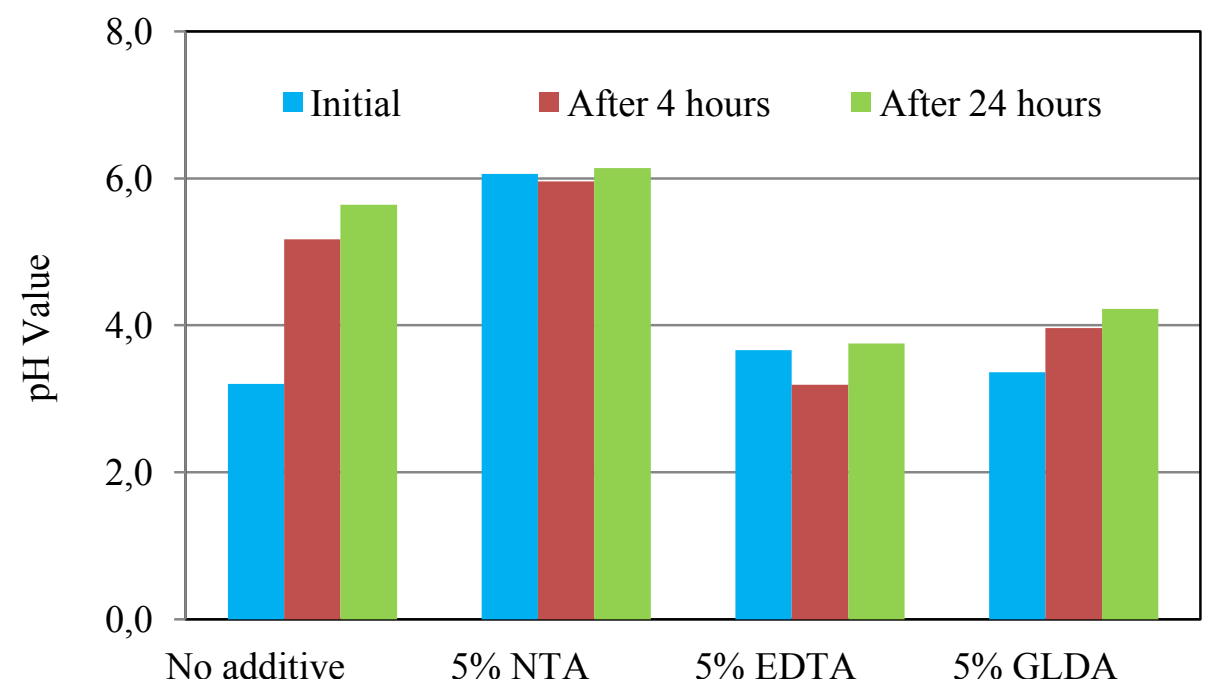

Figure 13. Change of $\mathrm{pH}$ value in THPS dissolver solution. 
The most significant change in scale composition was the formation of new calcium sulfate scales in tests with scale \#A (Figure 15). Large amounts of gypsum $\left(\mathrm{CaSO}_{4} \cdot 2 \mathrm{H}_{2} \mathrm{O}\right)$ were found in most samples (Figure 16), except for dissolvers with phosphonate additives and high THPS (75\%) concentration. In the test with 75\% THPS, a small amount of hemihydrate $\left(\mathrm{CaSO}_{4} \cdot 1 / 2 \mathrm{H}_{2} \mathrm{O}\right)$, instead of gypsum, was detected (Figure 15). The new calcium sulfate minerals was formed with reaction between calcium ions released from calcite dissolution and sulfate ions associated with THPS (Figure 17). Phosphonate additives inhibited the dissolution of calcite and prevented the formation of gypsum.
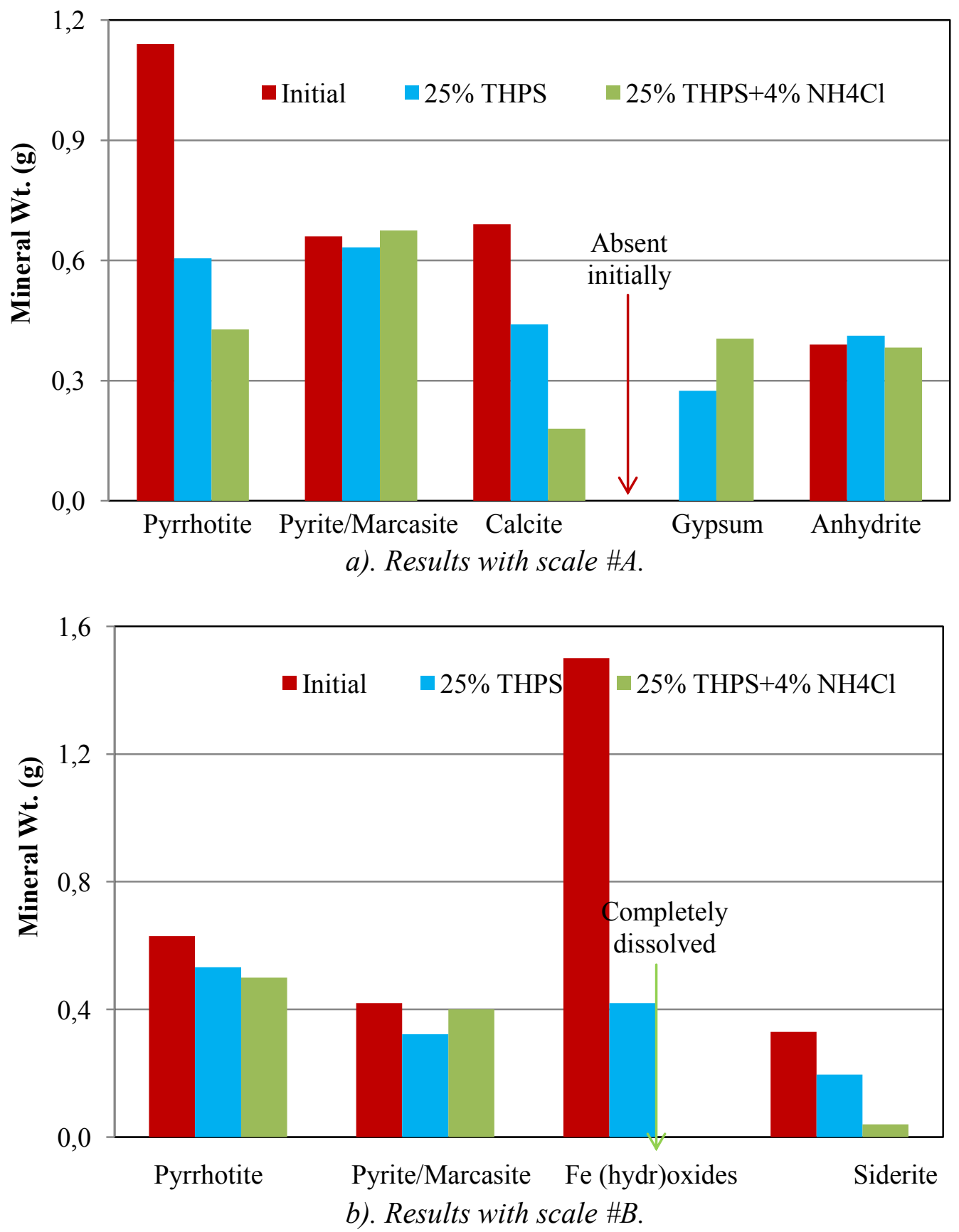

Figure 14. Weight changes for individual scale mineral. 


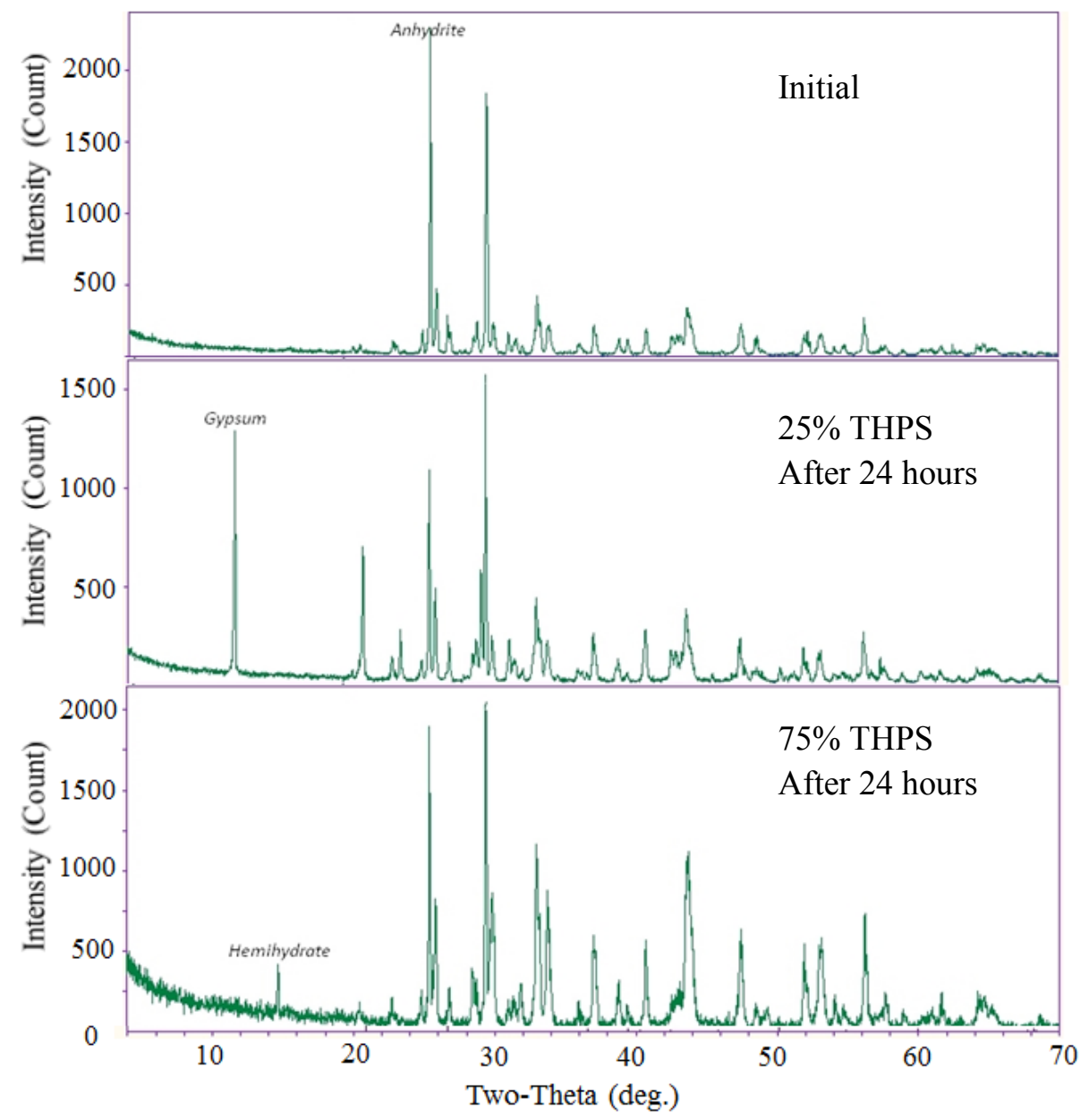

Figure 15. XRD patterns of initial and final scale solids.
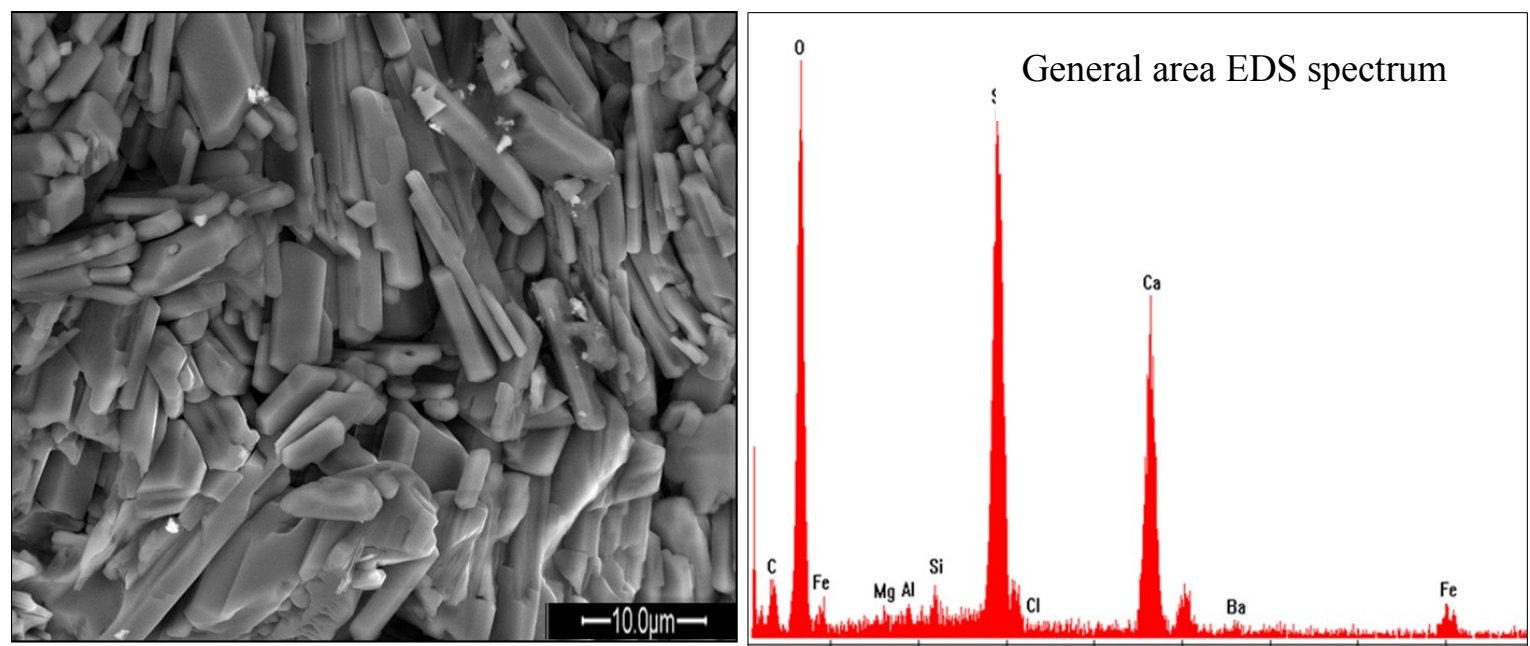

Figure 16. Gypsum crystals formed due to calcite dissolution. 


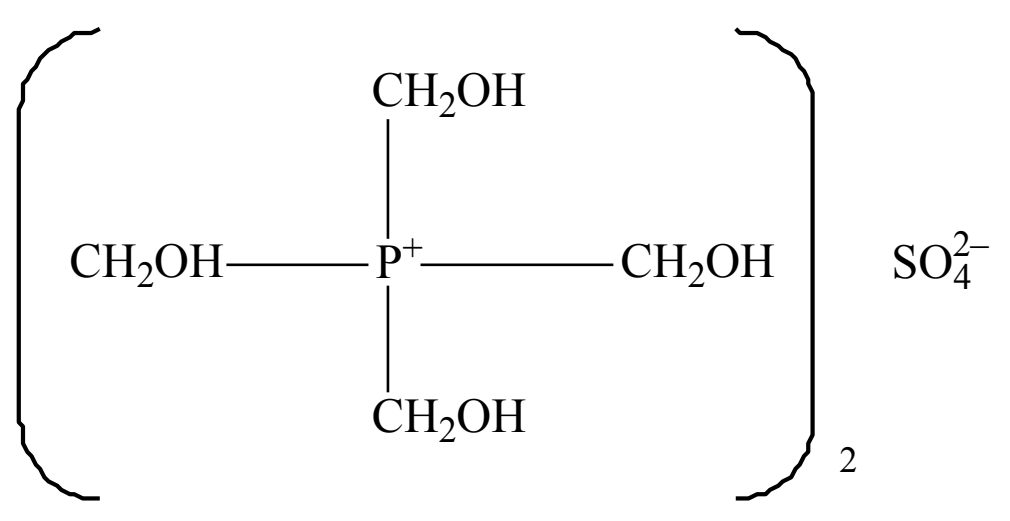

Figure 17. THPS chemical structure $(\mathrm{MW}=406.28)$.

\section{Conclusions}

This study evaluated THPS as dissolver for scale deposits formed in high temperature sour gas wells. These deposits have mixed minerals including iron sulfides, iron oxyhydroxides, iron carbonate, calcium carbonate and calcium sulfate. Test results suggest that the dissolving power is not strongly related to THPS concentration in the tested range of 15 to $75 \%$. Depending on scale composition, maximum dissolution was achieved at 25 to $50 \%$ THPS. The dissolving power of THPS solution can be significantly enhanced with ammonium chloride. This improvement was largely associated with $\mathrm{pH}$ decrease due to thermal decomposition of ammonium ions. As a result, the corrosivity to mild steel was increased. Addition of chelating agents, such as NTA, EDTA and GLDA, also increased the scale dissolution. Although this synergistic effect was also affected by $\mathrm{pH}$, scale dissolution was improved even at increased $\mathrm{pH}$ level. The performance of THPS was deteriorated by two phosphonate compounds, DETPMP and BHTPMP. They interfered with scale dissolution and also induced re-precipitation.

Study results also reveal the selective dissolution of mixed scale by THPS. Iron oxyhydroxides were highly reactive in the THPS solution, followed by calcite, siderite and pyrrhotite. The THPS based dissolver was not effective to iron disulfides (pyrite and marcasite) and anhydrite. Additionally, this study shows that calcium sulfate could be formed during calcite dissolution with THPS. Therefore, THPS based dissolver should not be used for scales containing large amounts of calcium carbonate.

\section{Acknowledgments}

The authors wish to acknowledge Saudi Aramco for granting permission to publish this paper. They also like to thank Chemical Analysis Unit in the R\&D Center for the analytical works. 


\section{References}

1. S. Y. Lu and I. Hamerton, Prog. Polym. Sci., 2002, 27, 1661.

2. A. R. Horrocks, Polym. Degrad. Stabil., 2011, 96, 377.

3. N. N. Fathima, J. Am. Leather Chem. As., 2011, 106, 249.

4. D. L. Gallup, S. Yean and H. Mogaddedi, Synth. React. Inorg. M., 2013, 43, 1274.

5. D. Xu, W. Huang, G. Ruschau, J. Hornemann, J. Wena and T. Gu, Eng. Fail. Anal., 2013, 28, 149.

6. J. E. Gittens, T. J. Smith, R. Suleiman and R. Akid, Biotechnol. Adv., 2013, 31, 1738.

7. R. E. Talbot, J. Larsen and P. F. Sanders, CORROSION/2000, Houston, paper no. 00123.

8. B. L. Downward, R. E. Talbot and T. K. Haack, CORROSION/97, Houston, 1997, paper No. 401.

9. C. Jones, B. Downward, S. Edmunds, T. Curtis and F. Smith, CORROSION/2012, Houston, 2012, paper no. 1505.

10. K. Zhao, J. Wen, T. Gu, A. Kopliku and I. Cruz, Mater. Perform., 2008, 48, 62.

11. N. N. Fathima, M. C. Bose, J. R. Rao and B. U. Nair, J. Inorg. Biochem., 2006, 100, 1774.

12. K. Zhao, J. Wen, T. Gu, A. Kopliku and I. Cruz, CORROSION/2008, Houston, 2008, paper no. 512.

13. R. E. Talbot, P. D. Gilbert, M. A. Veale, J. M. Grech and K. Hernandez, CORROSION/ 2002, Houston, 2002, paper no. 02030.

14. M. L. Walker, W. R. Dill and M. R. Besler, J. Pet. Technol., 1990, 43, 603.

15. J. J. Wylde and I. G. Winning, CORROSION/2004, Houston, 2004, paper no. 04730.

16. D. Rickard and G. W. Luther, Chem. Rev., 2007, 107, 514.

17. A. M. Anderko and P. J. Shuler, CORROSION/2002, Houston, 2002, paper no. 98064.

18. J. L. Przybylinski, International Symposium on Oilfield Chemistry, Houston, TX, 2001, paper no. 65030.

19. H. A. Nasr-E1-Din and A. Y. A1-Humaidan, 3rd International Symposium on Oilfield Scale, Aberdeen, 2001, paper no. 68315.

20. Q. Wang, H. Ajwad, T. Shafai and J. D. Lynn, SPE Technical Symposium \& Exhibition, Al-Khobar, 2013, paper no. 168063.

21. I. A. Zaafarany1 and H. A. Ghulman, Int. J. Corros. Scale Inhib., 2013, 2, no. 2, 82.

22. I. A. Zaafarany, Int. J. Corros. Scale Inhib., 2014, 3, no.1, 1.

23. A. Frignani, C. Monticelli, F. Zucchi and G. Trabanelli, Int. J. Corros. Scale Inhib., 2014, 3, no. 2, 105. 
24. V. P. Grigor'ev, E. V. Plekhanova, E. E. Verbitskaya and L. D. Popov, Int. J. Corros. Scale Inhib., 2014, 3, no. 4, 215.

25. J. Al-Tammar, M. Bonis, Y. Salim and H. J. Choi, SPE International Oilfield Corrosion Conference and Exhibition, Aberdeen, 2014, paper no. 169618.

26. S. Ramachandran, J. Leal, G. A. Muntasheri and Q. Wang, SPE International Symposium on Oilfield Chemistry, Woodland, 2015, paper no. 173713.

27. M. A. Kasnick and R. J. Engen, SPE Middle East Oil Show, Bahrain, 1989, paper no. 17933.

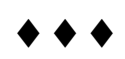

